\title{
Gravidez de adolescentes na mídia impressa
}

\author{
Adolescent pregnancy in the printed media
}

Embarazo de adolescentes en la prensa

\section{Sonia Regina Schena Bertol ${ }^{1}$}

- Doutora em Comunicação Social pela Universidade Metodista de São Paulo (Umesp)

- Doutorado-sanduíche na Johns Hopkins University (EUA)

- Professora e pesquisadora da Universidade de Passo Fundo (UPF)

- Coordenadora do Curso de Jornalismo da UPF

- Autora do livro Tarso de Castro, editor de O Pasquim

- Tem experiência na área de comunicação, com ênfase em comunicação da saúde e divulgação científica

- E-mail: sobertol@upf.br

\footnotetext{
1 Este trabalho contou com a colaboração das alunas de Jornalismo da Universidade de Passo Fundo (UPF) Vanessa Lazzaretti (bolsista de iniciação científica) e Ingra Costa e Silva (voluntária de iniciação científica).
} 


\section{Resumo}

A comunicação é uma das principais ferramentas para intervir na saúde, pois utiliza estratégias para informar e influenciar as decisões dos indivíduos, no sentido de promoverem sua saúde. No caso da gravidez na adolescência, grande parte da percepção que se tem sobre o tema advém da abordagem feita pela mídia impressa. Sendo assim, desenvolvemos um estudo por meio do qual se procura analisar os principais enfoques que o tema recebe na mídia local, na mídia estadual e na mídia nacional. Para tanto, foram escolhidos, respectivamente, O Nacional, de Passo Fundo (RS), Zero Hora, de Porto Alegre (RS), e a Folha de S.Paulo. O presente artigo atém-se exclusivamente à verificação da presença do tema na mídia local, representada por O Nacional, seguindo um protocolo de análise elaborado para este fim.

PALAVRAS-CHAVE: GRAVIDEZ NA ADOLESCÊNCIA • MÍDIA IMPRESSA • ANÁLISE DE ENQUADRAMENTO

\section{Abstract}

The communication is one of the main tools to intervene in health, because it uses strategies to inform and influence individuals' decisions to promote their health. In the case of teenage pregnancy, much of the perception that one has on the topic stems from the approach given by the print media. Thus, the purpose of this study is to verify this issue in the local media, in the media of the State of Rio Grande do Sul, and the national media, represented, respectively, by the newspaper O Nacional (Passo Fundo, RS), Zero Hora (Porto Alegre, RS) and Folha de S.Paulo. In this text we analyze the main approaches to the this in $O$ Nacional, following an analysis protocol developed for this purpose.

\section{KEYWORDS: TEENAGE PREGNANCY • PRINT MEDIA・FRAMING ANALYSIS}

\section{Resumen}

La comunicación es una de las principales herramientas para intervenir en la salud, porque utiliza estrategias para informar e influenciar las decisiones de los individuos, en función de promover su salud. En el caso de embarazo en la adolescencia, gran parte de la percepción que se tiene sobre el tema adviene del abordaje realizado por la prensa. En ese sentido, desarrollamos un estudio, por medio del cual se pretende analizar los principales enfoques que el tema recibe en los medios locales, los medios estaduales y los medios nacionales. Para eso fueron escogidos, respectivamente, O Nacional (Passo Fundo, RS), Zero Hora (Porto Alegre, RS) y Folha de S.Paulo. El presente artículo se preocupa exclusivamente a la presencia del tema en los medios de comunicación locales, representados por el periódico O Nacional, siguiendo un protocolo de análisis desarrollado para ese propósito.

PALAVRAS CLAVE: EMBARAZO EN LA ADOLESCENCIA • PRENSA - ANÁLISIS DE ENCUADRAMIENTO 

onsiderando que os jornais são uma janela para o mundo, a forma como as notícias são apresentadas neles moldam a opinião pública e direcionam o debate sobre determinado tema. Ponderamos que a percepção do objeto de estudo "gravidez na adolescência" advém em grande parte de sua abordagem pela mídia impressa. Este artigo se detém na verificação desse tema na mídia local, representada pelo jornal O Nacional, de Passo Fundo (RS). Ele faz parte de um estudo mais amplo, que inclui a mesma pesquisa na mídia estadual, representada pelo jornal Zero Hora, de Porto Alegre (RS), e na mídia nacional, representada pelo jornal Folha de S. Paulo. Em cada uma das esferas, esses periódicos são considerados de referência, tanto por sua história quanto por sua circulação e influência editorial. Nesses veículos buscamos nosso material de análise, inicialmente no veículo mencionado de Passo Fundo - concretamente, neste capítulo, no qual também fazemos a fundamentação teórica do estudo. O conjunto da análise das três amostras, inclusive de forma comparativa, levará à compreensão de como a gravidez na adolescência vem sendo enquadrada em cada uma das esferas.

\section{GRAVIDEZ NA ADOLESCÊNCIA: UMA VISÃO HOLÍSTICA}

Hoje o grande público começa a se interessar cada vez mais pela informação científica trazida pelos periódicos e por diversos produtos editoriais que têm se preocupado exclusiva ou complementarmente com a divulgação da ciência e da medicina. Então, também é hora de qualificar sua cobertura. Nesse quadro surge a importante presença do comunicador, suscitando interesse e curiosidade, promovendo programas de promoção da saúde pública e de prevenção de doenças coletivas na agenda midiática. Quanto à exclusão das grandes das benesses das ciências médicas, José R. Carvalheiro (1999, p. 7) lembra:

O mundo contemporâneo assiste a uma dramática deterioração das condições gerais de vida e saúde de segmentos cada vez maiores da população. Uma agenda de discussões carregada faz parte do repertório dos teóricos, políticos, empresários e trabalhadores; enfim, de toda a população. Uma ampla diversidade dessa agenda torna difícil identificar a importância relativa de cada um dos grandes temas atualmente em debate, tanto no Brasil quanto (especialmente) no exterior. Não passa despercebido, no entanto, o crescente interesse pelo que está ocorrendo na área. As razões mais evidentes a justificar esse interesse poderiam ser de natureza humanitária, diante da vergonhosa situação da saúde em grande parte do mundo.

Parece preocupante a situação da saúde na contemporaneidade, como um bem de acesso restrito àqueles que podem pagar pelos seus altos custos, como lembra o ex-ministro da Saúde José Serra (1999 p. 39):

Os meios de prevenção e tratamento das doenças foram se tornando mais sofisticados e caros. Não apenas face aos frutos crescentes da tecnologia, mas também porque, no passado, 
existiam mais doenças sem possibilidade de tratamento e estas possibilidades foram sendo abertas ao longo do tempo.

A pesquisadora Virginia Silva Pintos (2003, p. 123) considera que

a saúde sofreu uma transformação substancial de paradigma nos últimos anos. De uma perspectiva que privilegiava a medicina como único fator de proteção sanitária, se chegou a uma visão que transcende o problema médico para implicar o entorno físico-ambiental e a situação econômico-social do indivíduo. A saúde, como conceito, foi desenvolvendo novos sentidos; transcendeu a esfera enfermidade/curativa (ausência de enfermidade), para abranger aspectos mais globais: alimentação, moradia, segurança, educação, nível socioeconômico, ecossistema, justiça social, igualdade e paz².

A saúde é um fenômeno multidimensional, que envolve aspectos físicos, psicológicos e sociais, todos interdependentes. A representação comum de saúde e doença como extremos opostos unidimensionais é muito enganadora. Frijot Capra (1982, p. 301) ressalta que

a doença física pode ser contrabalançada por uma atitude mental positiva e por um apoio social, de modo que o estado global seja de bem-estar. Por outro lado, problemas emocionais ou o isolamento social podem fazer uma pessoa sentir-se doente, apesar de seu bom estado físico. Essas múltiplas dimensões da saúde afetam-se mutuamente, de um modo geral; a sensação de estar saudável ocorre quando tais dimensões estão bem equilibradas e integradas. A experiência de doença resulta de modelos de desordem que podem se manifestar em vários níveis do organismo, assim como nas várias interações entre o organismo e os sistemas mais vastos em que ele está inserido.

A saúde, portanto, é uma experiência de bem-estar resultante de um equilíbrio dinâmico que envolve os aspectos físicos e psicológicos do organismo, assim como suas interações com o meio ambiente natural e social.

Nessa busca pelo equilíbrio, vem se difundindo uma abordagem holística da saúde, que, em vez de ênfase em medicamentos e cirurgias que buscam concertar o defeito de determinada parte do organismo, privilegia as técnicas não agressivas que buscam a integridade corpo-mente. Isso não quer dizer que as cirurgias e os medicamentos deixem de ser utilizadas. Contudo, esses recursos passam a ser aplicados em conjunto com técnicas não agressivas, como exercícios físicos, danças, meditação, entre outras, para que não apenas o lado físico seja tratado, mas o psicológico também.

\footnotetext{
2 Tradução nossa.
} 
Este entrelaçamento entre o social e o biológico, entretanto, vem sendo reivindicado até hoje. Luis Ramiro Beltrán (2001) aponta ainda a reafirmação da importância dos conceitos de promoção da saúde e de prevenção da doença quando representantes de 134 países se reuniram na ex-União Soviética em 1978, em evento promovido pela Organização Mundial da Saúde (OMS. Daí derivou a Declaração de Alma-Ata, conceitos que também seriam adotados pelo governo dos Estados Unidos no ano seguinte e que ganhariam grande amplitude em 1986, quando a OMS promoveu a Primeira Conferência Internacional sobre Promoção da Saúde, no Canadá. Desta resultou um documento denominado Carta de Ottawa, "que definiu a promoção da saúde como o processo que consiste em proporcionar aos povos os meios necessários para melhorar sua saúde e exercer maior controle sobre ela" (Beltrán, 2001b, p. 358). Tanto a reunião de Alma-Ata quanto a de Otawa tiveram a preocupação de demonstrar também a importância da comunicação dentro desse novo paradigma de promoção da saúde: "Visto que por definição a promoção deve alcançar seus fins por persuasão, não por coerção, se atribui universalmente à comunicação a qualidade de instrumento-chave para materializar tal política de saúde" (Beltrán, 2001b, p. 361)3.

A importância da divulgação científica e, dentro dela, de temas correlatos à saúde, vem referendando a consolidação da especialidade da comunicação da saúde. A relação entre comunicação e saúde veio se afirmando paulatinamente nos últimos anos; profissionais desses campos reconheceram e provaram que eles constituem dimensões da vida cuja articulação (ou ausência de) afeta de maneira direta a saúde e, em um sentido mais amplo, a qualidade de vida dos indivíduos, as famílias e as sociedades:

A comunicação para a saúde (ou comunicação em saúde) se refere não apenas a difusão e análises da informação,

atividade comumente denominada jornalismo científico ou jornalismo especializado em saúde, mas se refere também à produção e aplicação de estratégias comunicacionais "massivas e comunitárias" orientadas à prevenção, proteção sanitária e à promoção de estilos de vida saudáveis, assim como ao planejamento e implemento de políticas de saúde e educação mais globais (Pintos, 2000, p.122). ${ }^{4}$

Quando uma adolescente engravida, geralmente ela se vê numa situação não planejada e até mesmo indesejada. Na maioria das vezes a gravidez na adolescência ocorre entre a primeira e a quinta relação sexual. E quando a jovem tem menos de dezesseis anos, por sua imaturidade física, funcional e emocional, crescem os riscos de complicações como aborto espontâneo, parto prematuro, maior incidência de cesárea, ruptura dos tecidos da vagina durante o parto, dificuldades na amamentação e depressão. Por tudo isso, a maternidade antes dos dezesseis anos é desaconselhável.

\footnotetext{
${ }^{3}$ As traduções de Beltrán são nossas.

4 Tradução nossa.
} 
Para se analisar o comportamento reprodutivo das mulheres na América Latina, é importante abordar o período da adolescência por suas implicações sociais e econômicas. Segundo dados do Instituto Brasileiro de Geografia e Estatística (IBGE), há um claro vínculo entre gravidez na adolescência e pobreza, revelado pela concentração de mães adolescentes pertencentes aos estratos de renda mais pobres. Assim, quando se analisa o nível educacional das mulheres, é possível verificar que quase metade das que não completaram o ensino fundamental foram mães adolescentes, contra apenas $7 \%$ das que completaram o segundo grau. A forte relação entre maternidade na adolescência e pobreza traz à tona um dos mecanismos de reprodução biológica da pobreza, que se traduz nas elevadas taxas de mortalidade infantil, desnutrição e outras graves carências da infância.

Como referimos acima, a saúde, enquanto conceito, vem se desenvolvendo e abrangendo questões mais globais, como a educação e a condição socioeconômica na qual os cidadãos estão inseridos e, para implementar as políticas de saúde, segundo o próprio entendimento da Organização Mundial da Saúde, a comunicação é uma peça-chave, persuadindo os cidadãos a adotarem e manterem comportamentos saudáveis. Assim, acreditamos profundamente que a análise das mensagens emitidas pela mídia impressa sobre a gravidez na adolescência, num panorama local, estadual e nacional, nos fornecerá diversos subsídios de como a questão da gravidez na adolescência vem sendo enquadrada pelos jornais selecionados para o presente projeto. Esses subsídios nos iluminarão na compreensão do ângulo que o debate sobre esse importante tema vem ganhando na mídia impressa e, a partir daí, buscar caminhos para o seu aperfeiçoamento.

\section{COMUNICAÇÃO DA SAÚDE}

É inegável a emergência do campo da comunicação da saúde, principalmente na última década, considerada como uma especialidade da subárea da comunicação científica. Universidades, associações de pesquisadores, publicações da área, organismos governamentais e diversas organizações voltadas para a saúde, no mundo todo, vêm demonstrando interesse em conhecer seus preceitos, utilizar suas estratégias, impulsionar seu crescimento. E isso, como procuraremos demonstrar a seguir, derivou também de uma nova visão da saúde, a qual estaria mais voltada para noções de promoção da saúde e de prevenção da doença, da qual a comunicação não pode estar separada. A prevenção é parte preponderante de um processo que inclui a apresentação e a avaliação de informação educativa, persuasiva, significante e atraente, que possa influenciar na mudança de comportamento e resultar em comportamentos individuais e sociais sadios. Como lembra Rina Alcalay (1999, p. 192-193),

a importância da comunicação no âmbito da saúde é clara. Existe uma disparidade entre os avanços da medicina e o conhecimento e a aplicação destes para o público. Ainda que os profissionais da saúde tenham grandes conhecimentos sobre a prevenção das enfermidades e a promoção da saúde, não sabem necessariamente como comunicar efetivamente essa informa- 
ção tão vital para a sociedade. Essa situação constitui o foco central do interesse da área de comunicação para a saúde, quer dizer, o estudo da natureza e a função dos meios necessários para fazer com que os temas de saúde cheguem às audiências e produzam efeito nelas. ${ }^{5}$

Novas maneiras de olhar a saúde estão sendo reveladas nos últimos anos, ampliando-se a compreensão de que ela se relaciona diretamente com o contexto e com o entorno físico-ambiental e a situação socioeconômica-cultural do indivíduo. Assim, ao se pensar na saúde, passou-se a considerar aspectos mais globais, como alimentação, moradia, segurança, educação, nível socioeconômico, ecossistema, justiça social, igualdade e paz. Da agenda contemporânea dos temas de saúde vêm fazendo parte a promoção e o fomento da adoção e manutenção de estilos de vida saudáveis por parte da população. Sendo assim, a ideia presente hoje, que sintetiza o conceito de saúde adotado pela Organização Mundial da Saúde, é de que a saúde é um estado de bem-estar positivo, associado à adoção de atitudes, potencialidades e qualidades e não à mera ausência de enfermidades. Isso reforçou mais ainda a relevância dos programas comunicacionais, tendo a saúde encontrado na comunicação um componente fundamental e indispensável dentro dessa nova visão.

Esses são alguns dos motivos que, de acordo com Charles Salmon (1992), fazem da comunicação da saúde, enquanto intervenção um fenômeno que pode gerar muitas mudanças sociais:

Os pressupostos que fundamentam esse quadro mostram que as intervenções em saúde são vistas como fenômenos de mudança social em que os formuladores de políticas, planejadores, profissionais, ou outros, têm o objetivo de influenciar a saúde por meio de atitudes, comportamentos físicos e sociais. ${ }^{6}$

A intervenção e a comunicação em saúde surgem não só como uma estratégia para prover indivíduos e coletividade de informação, pois reconhece-se que a informação não é o suficiente para favorecer mudanças, mas é uma chave, dentro do processo educativo, para compartilhar conhecimentos e práticas que podem contribuir para a conquista de melhores condições de vida. Reconhece-se que a informação de qualidade, difundida no momento oportuno, com a utilização de uma linguagem clara e objetiva, é um poderoso instrumento de promoção da saúde. O processo de comunicação deve ser ético, transparente, atento a valores, opiniões, tradições, culturas e crenças da comunidade, respeitando, considerando e reconhecendo as diferenças. Deve ainda apresentar informações educativas, interessantes, atrativas e compreensíveis, para assim alcançar os objetivos almejados.

\footnotetext{
5 Tradução nossa.

6 Tradução nossa.
} 
No cenário apresentado por Beltrán (2001a), ele remonta à Europa do início do século XIX, entre 1820 e 1840, quando os médicos William Alison, escocês, e Louis René Villermé, francês, estabeleceram relações entre pobreza e enfermidade. Na experiência do médico francês, pôde-se comprovar que as duras condições de vida e trabalho sob as quais viviam operários têxteis causavam sua morte prematura. Nesses estudos estaria centrada, segundo Beltrán, a noção extremamente atual de promoção da saúde, na qual a comunicação se engaja como um instrumento indispensável.

Beltrán (2001a) situou 1848 como um ano de suma importância dentro dessa mesma visão, quando se promoveu um movimento de reforma no conceito tradicional da medicina praticada na Alemanha. Esse movimento preconizava a atuação da medicina como ciência social e difundia uma visão da saúde como algo da responsabilidade de todos, não apenas do médico, cabendo ao Estado o papel de assegurá-la.

Mas somente um século depois essas ideias tiveram ressonância, quando o médico francês Henry Sigerist, então fixado nos Estados Unidos, despontou como historiador da medicina, revalorizando-as, reafirmando a noção de promoção da saúde e acrescentando as noções de prevenção e de cura. De seus ideais difundidos no início da década de 1940 repercutiram influências sobre a Organização Mundial da Saúde, que passou a adotar o conceito segundo o qual a saúde é um estado de bem-estar físico, mental e social e não simplesmente a ausência de dores ou enfermidades, como havíamos citado anteriormente.

Segundo Pintos (2002), o encontro das duas disciplinas - comunicação e saúde - foi constituindo uma área profissional específica e com intenções concretas:

- $\quad$ Assegurar uma adequada cobertura dos temas da saúde por parte dos meios massivos;

- Diminuir a brecha existente entre avanços da medicina e a incorporação destes pela população;

- Estudar as estratégias e os meios necessários para conseguir que as temáticas da saúde alcancem os públicos objetivos e produzam neles efeitos concretos;

- Motivar a população para temas como políticas de saúde e qualidade de vida;

- Gerar ações efetivas em favor da prevenção da enfermidade, da proteção e promoção da saúde integral.

O ano 1996 vem sendo lembrado como um marco importante para a consolidação da comunicação em saúde. Foi quando o primeiro número da revista Journal of Health Communication, da George Washington University, definiu o seguinte conceito de comunicação em saúde e antecipou sua difusão nos Estados Unidos e no resto do mundo:

Um campo de especialização dos estudos comunicacionais que inclui os processos de agenda setting para os assuntos de saúde: o envolvimento dos meios massivos com a saúde; a comu- 
nicação científica entre profissionais da biomedicina, a comunicação médico/paciente; e, particularmente, o planejamento e a avaliação de campanhas de comunicação para a prevenção da saúde (Ratzan; Payne, Bishop,1996).

No primeiro número da revista, um texto de autoria do pesquisador norte-americano Everett Rogers, intitulado "Up-to-date report" (Rogers, 1996, p. 15), ratifica a importância da comunicação da saúde, lembrando que esta começou em 1971, com o Stanford Heart Disease Prevention Program. Nesse programa, um cardiologista e um estudante de comunicação planejaram uma campanha de promoção da saúde que foi implementada em diversas comunidades da Califórnia. Sua concepção incluiu mensagens na mídia promovendo exercícios regulares, parar de fumar, mudanças na dieta e redução do stress. O programa estava baseado em três princípios teóricos: teoria do aprendizado social (Albert Bandura), teoria do marketing social (Philip Kotler e Eduardo L. Roberto) e teoria da difusão de inovações (Everett M. Rogers). Estes formaram a base de intervenções da comunicação desde então. Sobre o Stanford Heart Disease Prevention Program, bem como sobre a associação da comunicação com a saúde, Alcalay (1999, p. 192) recorda que

a origem dessa área de especialização em comunicação para a saúde se atribui a um projeto em particular, o Stanford Heart Disease Prevention Project ${ }^{7}$, dirigido pelo doutor Jack Farquahar, cardiologista, e pelo doutor Nathan Maccoby, professor de comunicação. Reconhecendo a importância dessa área de estudo, o governo dos Estados Unidos estabeleceu em 1993 a Oficina de Comunicação e Saúde localizada nos Centros para o Controle e a Prevenção de Doenças (CDC).

Todo o quadro ascendente da comunicação da saúde vai ao encontro de nossa visão de que a evolução da medicina, da genética e das ciências humanas, entre outras, significa, também, o desenvolvimento do próprio homem. E é justamente na divulgação de sua evolução que se encontram possibilidades concretas para estender o novo conhecimento à sociedade, sendo primordial o papel do comunicador como "tradutor" entre as inovações surgidas e aquilo de que o público toma conhecimento.

\section{GRAVIDEZ NA ADOLESCÊNCIA, PROBLEMA EM ASCENSÃO}

Atualmente há um aumento significativo de casos de gravidez em adolescentes. Em 1990, cerca de $10 \%$ das gestações ocorriam nessa faixa etária. Em 2000, portanto apenas dez anos depois, esse índice aumentou para $18 \%$, ou seja, praticamente dobrou o número de mulheres que engravidam entre doze e dezenove anos. Apesar de hoje a sociedade ter se modernizado e as mulheres terem adotado um outro estilo de vida, e, principalmente, apesar da divulgação de métodos contraceptivos, "a cada ano mais jovens engravidem numa idade em que outras ainda dormem abraçadas com o ursinho de pelúcia" (Varela, 2007). A gravidez na adolescência é considerada de alto risco.

\footnotetext{
7 Projeto de prevenção das doenças do coração, de Stanford.
} 
Os dados do Ministério da Saúde (MS, 2007) também ratificam que, no Brasil, a gravidez entre os quinze e dezenove anos cresceu, contrariando a tendência geral de diminuição das taxas de fecundidade. A Pesquisa Nacional de Demografia e Saúde (PNDS) realizada em 1996 demonstrou que $14 \%$ das mulheres nessa faixa etária tinham pelo menos um filho e que as jovens mais pobres tinham mais filhos do que as de melhor nível socioeconômico. Além disso, observou-se um aumento no percentual de partos de adolescentes de dez a catorze anos atendidas pela rede do SUS e, também, de curetagem pós-aborto. Na opinião dos especialistas, os dados evidenciam que "esta realidade, de origem multicausal, revela deficiências na implementação de políticas públicas, exigindo um movimento do governo e da sociedade para promover a saúde e o desenvolvimento da juventude" (MS, 2007).

Consideramos muito significativo, ainda, o que indica o trabalho "Indicadores sobre crianças e adolescentes: Brasil, 1991-1996" (IBGE-Unicef, 1997), realizado pelo Instituto Brasileiro de Geografia e Estatística (IBGE) e pelo Fundo das Nações Unidas para a Infância (Unicef). "Existe um acentuado vínculo entre a gravidez na adolescência, a pobreza e o nível educacional: quase metade das mães adolescentes não completaram o $1^{\circ} \mathrm{grau}$ ". Isso implica diretamente o fato de que a relação entre a maternidade na adolescência e a pobreza traz à tona graves problemas, como taxas de mortalidade infantil, desnutrição e outras carências à infância brasileira. Aquele trabalho também divulgou, entre outros dados, que no Sudeste $12,3 \%$ da população com mais de quinze anos tiveram filhos e no Nordeste, $13,6 \%$ nessa faixa de idade já é mãe.

Sendo assim, consideramos que a comunicação da saúde constitui um instrumento fundamental para oferecer meios de evitar ou postergar a segunda gravidez e as gravidezes seguintes. Ela conscientiza as adolescentes quanto a todas as implicações que a gravidez acarretará para sua vida adulta, orientando-as para uma vida saudável, o que pode ser visto como um direito de cidadania a ser assegurado.

\section{ANÁLISE DE CONTEÚDO}

Para explorar as questões de pesquisa expostas acima, decidimos examinar os textos jornalísticos selecionados para este estudo, usando quantitativa e qualitativamente a técnica da análise de conteúdo, cuja história foi descrita por Laurence Bardin (1977). O autor pontuou então que essa prática funcionava havia mais de meio século, tendo sido antecedida por diversas formas de abordar os textos, "de tradição longínqua" (Bardin, 1977, p. 14), como, por exemplo, pela hermenêutica, pela retórica e pela lógica. Afirma ele que o nome que de fato ilustra seu aparecimento é o do pesquisador norte-americano Harold Lasswell, ao empreender análises de imprensa e de propaganda desde 1915:

Desde o princípio do século, durante cerca de quarenta anos, a análise de conteúdo desenvolveu-se nos Estados Unidos. Nesta época o rigor científico invocado é o da medida, e o material 
analisado é essencialmente jornalístico. A Escola de Jornalismo da Colúmbia dá o pontapé de saída e multiplicam-se assim os estudos quantitativos dos jornais (Bardin, 1977, p. 15).

Sola Pool (apud Bardin, 1977, p. 20-21) resumiu as novas concepções que foram orientando a análise de conteúdo com o passar do tempo, as quais seriam divididas em "instrumental" e "representacional":

De maneira grosseira, arrogamo-nos o direito de dizer que "representacional" significa que o ponto importante no que diz respeito à comunicação é o revelado pelo conteúdo dos itens léxicos nela presentes, isto é, que algo nas palavras da mensagem permite ter indicadores válidos sem que se considerem as circunstâncias, sendo a mensagem o que o analista observa. Grosso modo, "instrumental" significa que o fundamental não é aquilo que a mensagem diz à primeira vista, mas o que ela veicula dados os seus contextos e as suas circunstâncias.

A partir daí determina-se que a função da análise de conteúdo não é mais meramente descritiva, surgindo a importante noção de inferência: "A intenção da análise de conteúdo é a inferência de conhecimentos relativos às condições de produção (ou, eventualmente, de recepção), inferência esta que recorre a indicadores (quantitativos ou não)" (Bardin, 1977, p.38).

$\mathrm{Na}$ análise dos textos jornalísticos que consideraremos para nossa investigação, tentaremos reter fielmente as noções apresentadas acima. Isto é, de que essa técnica da análise de conteúdo nos fornecerá especialmente inferências que poderão ser extraídas das mensagens, com base nos seus enquadramentos, ou seja, oriundas do nosso esquema de interpretação de acordo com o referencial da análise de enquadramento. À medida que as informações obtidas são confrontadas com as existentes, pode-se chegar a amplas generalizações, o que torna a análise de conteúdo um dos mais importantes instrumentos para a análise das comunicações de massa. É, portanto, um conjunto de técnicas de análise das comunicações, visando, por procedimentos sistemáticos e objetivos de descrição do conteúdo das mensagens, obter indicadores, quantitativos ou não, que permitam a inferência de conhecimentos relativos às condições de produção/ recepção das mensagens.

Nessa fase, o pesquisador deve descobrir o conteúdo latente, não se detendo apenas no conteúdo manifesto. O conteúdo manifesto leva o pesquisador a apoiar-se em conclusões baseadas em dados quantitativos, numa visão estática e no patamar de simples denúncia de realidades negativas para o indivíduo e a sociedade. O conteúdo latente abre perspectivas, sem excluir a informação estatística, muitas vezes, para descobrir ideologias, tendências e enquadramentos dos fenômenos que se analisam. 


\section{ANÁLISE DE ENQUADRAMENTO}

Selecionar, excluir e ordenar fatos e informações é o que acontece a todo momento, durante o processo de produção da notícia. Esse processo é trabalhado pelo jornalista e dá forma à mensagem jornalística, que é considerada o reflexo da nossa realidade. No entanto, essa mensagem parte de um determinado enquadramento.

Adotado pelo jornalista para apresentar a notícia, o enquadramento pode ser entendido como o ângulo de abordagem entre os inúmeros desdobramentos que podem ser adotados para tratar de um mesmo assunto.

De acordo com Murilo César Soares (2006), a noção de enquadramento foi desenvolvida por norte-americanos, sendo a obra Frame analysis, do sociólogo Erving Goffman (1986), a referência principal sobre o assunto. Para esse sociólogo, os enquadramentos são definidos como marcos interpretativos construídos socialmente, que permitem às pessoas atribuir sentidos aos acontecimentos e às situações sociais, basicamente, respondendo à pergunta: "O que está acontecendo aqui?". Seguindo o pensamento de Goffman (1986), podemos dizer que enquadramentos são maneiras de interpretar e dar sentido ao que se passa ao nosso redor.

A socióloga Gaye Tuchman (1978) foi quem primeiro aplicou o conceito de enquadramento no campo dos estudos comunicacionais, defendendo que o enquadramento constitui uma característica das notícias. Há, portanto, forças que agem e influenciam durante a organização do discurso. O que faz o jornalista escolher uma informação e excluir outra, buscar uma determinada fonte ou destacar certos dados está ligado às ideias que formam o caráter do jornalista. Essas ideias estão relacionadas a preconceitos, modo de vida, condição econômica, posicionamento político, espaço, tempo, entre outros fatores.

Dessa forma, podemos afirmar que enquadramento é o modo pelo qual cada pessoa interpreta todas as coisas e lhes dá sentido a partir da eleição daquilo que lhe é compreensível e aceitável. Da mesma forma o jornalista, na prática, reproduz os fatos e as informações de acordo com sua interpretação e seu sentido.

No que se refere à área das notícias de saúde, inúmeros estudos vêm sendo realizados com o intuito de examinar seu enquadramento ou framing (Lima e Siegel, 1999; Menashe e Siegel, 1998; Meyerowitz e Chaiken, 1987). Julie C. Lima e Michael Siegel (1999), por exemplo, dedicaram-se a encontrar o enquadramento das notícias publicadas na mídia acerca do debate nacional sobre o tabaco nos Estados Unidos, durante os anos 1997-1998. Por meio de uma análise de conteúdo aplicada em artigos extraídos do jornal Washington Post, os pesquisadores examinaram as principais tendências de enfoque dessas notícias sobre o debate nacional das políticas do tabaco, considerado o debate mais importante sobre o tema na 
história recente daquele país, tendo estado presente nas manchetes dos jornais quase que diariamente durante aquele período. Dizem os autores

Porque a cobertura da mídia ao debate das políticas do tabaco durante 1997-1998 foi tão extensa, o modo pelo qual o problema do tabaco foi enquadrado durante este debate pode influenciar a formação das suas políticas de ação no futuro (Lima; Siegel, 1999, p. 247). ${ }^{8}$

A forma pela qual a mídia cobria a questão do regulamento do debate - portanto o seu framing ou seu enquadramento - fez os pesquisadores perceberem como os argumentos eram arranjados para definir o problema do tabaco. Não apenas se sugeria aos responsáveis por suas políticas e ao público por que o problema do tabaco é importante, mas definia as soluções apropriadas para o problema. "Em outras palavras, a mídia diz para as pessoas não somente sobre quais questões pensar, mas como pensar sobre as mesmas" (Lima; Siegel, 1999, p. 247). Para esses autores, a influência da mídia no modo como o público reage a uma questão de saúde pública é um resultado do enquadramento (framing) dessa questão. "Um frame é um modo de embalar e posicionar uma questão até que ela conduza a um certo significado" ( Lima; Siegel,1999, p. 247). Além disso, afirmam que o modo no qual uma questão de saúde pública é enquadrada, afeta a opinião pública, influencia o comportamento individual e desempenha um papel central no processo da formação das políticas de saúde pública (Lima; Siegel, 1999).

Lima e Siegel dizem que

é importante notar que nossa proposta aqui não é criticar a cobertura da mídia no regulamento do tabaco. Nós estamos simplesmente tentando caracterizar esta cobertura e considerar as potenciais implicações no modo como o debate foi enquadrado.

O estudo de Lima e Siegel (1999) tornou-se decisivo para demonstrar como questões da saúde podem sofrer diferentes interpretações da maneira como são estruturadas/enquadradas nas notícias da mídia, segundo a análise de conteúdo utilizada por eles com o aparato teórico metodológico da análise de enquadramento ou framing theory.

A framing theory ou análise de enquadramento considera que nas notícias ocorre mais do que apenas "trazer" ao público certos tópicos. O modo pelo qual as notícias são trazidas, o enquadramento (frame) no qual elas são apresentadas, é também uma escolha feita pelos jornalistas. Segundo Robert H. Wicks (2005, p.339),

\footnotetext{
${ }^{8}$ É nossa a tradução de citações de Lima e Siegel.
} 
frames tornam as pessoas aptas a avaliar, conduzir e interpretar informações baseando-se em construções conceituais compartilhadas. Desse modo, mensagens da mídia contêm sugestões contextuais oferecidas por comunicadores profissionais para ajudar pessoas a entender a informação. ${ }^{9}$

Assim, um frame representa o modo como a mídia e os editores da mídia organizam e apresentam as questões que eles cobrem, e o modo como as audiências interpretam o que eles estão oferecendo. Frames ou enquadramentos são noções abstratas que servem para organizar ou estruturar significados sociais. A framing theory ou análise de enquadramento também defende que a forma "como" algo é apresentado influencia nas escolhas que as pessoas fazem.

Ainda que a objetividade seja um objetivo de jornalistas profissionais, as mensagens construídas por eles sempre estarão carregadas por um conjunto de práticas ou tradições organizacionais e também por suas opiniões e crenças, resultando em mensagens como representações da realidade apresentada por seus próprios prismas. Orientações de cunho político ou econômico particulares de cada meio de comunicação, práticas organizacionais, as próprias crenças do comunicador e as estratégias para atrair audiências acabam influenciando no enquadramento das mensagens da mídia.

\section{Categorias de análise}

À luz da análise de conteúdo e da análise de enquadramento, construímos um protocolo com categorias de análise em consonância com os objetivos da comunicação da saúde, cujos conotadores são:

- $\quad$ Corpo, saúde, sexualidade e trajetórias contraceptivas na adolescência;

- Sexo seguro: prevenção da gravidez não desejada, das DSTs/aids e do câncer de colo uterino;

- Iniciação sexual e relações de gênero na gestação na adolescência;

- Rastreamento, diagnóstico e tratamento de doenças sexualmente transmissíveis;

- Educação sexual nas escolas e nos serviços de saúde.

Para analisar o enquadramento dado pela mídia ao tema gravidez na adolescência, elaboramos um protocolo de análise, que segue os parâmetros exibidos na tabela 1, a seguir.

\footnotetext{
9 Tradução nossa.
} 
Tabela 1 - Categorias de análise

\begin{tabular}{|c|c|c|c|c|c|}
\hline $\begin{array}{l}\text { Categorias } \\
\text { de análise }\end{array}$ & Gênero & Assunto & Argumento & Linguagem & Público-alvo \\
\hline $\begin{array}{l}\text { Corpo, saúde, } \\
\text { sexualidade e } \\
\text { trajetórias con- } \\
\text { traceptivas na } \\
\text { adolescência } \\
\end{array}$ & ----- & ----- & ----- & ----- & ----- \\
\hline $\begin{array}{l}\text { Sexo seguro: } \\
\text { prevenção da } \\
\text { gravidez não } \\
\text { desejada,das } \\
\text { DSTs/aids e } \\
\text { do câncer de } \\
\text { colo uterino. }\end{array}$ & ----- & ----- & ----- & ----- & ----- \\
\hline \begin{tabular}{|l} 
Iniciação \\
sexual e re- \\
lações de \\
gênero na \\
gestação na \\
adolescência \\
\end{tabular} & ----- & ---- & ----- & ----- & ----- \\
\hline $\begin{array}{l}\text { Rastreamen- } \\
\text { to, diagnóstico } \\
\text { e tratamento } \\
\text { de doenças } \\
\text { sexualmente } \\
\text { transmissíveis }\end{array}$ & ----- & --- & ----- & ----- & \\
\hline $\begin{array}{l}\text { Educação se- } \\
\text { xual nas esco- } \\
\text { las e nos } \\
\text { serviços de } \\
\text { saúde } \\
\end{array}$ & ----- & ----- & ----- & ----- & ----- \\
\hline
\end{tabular}

\section{Análise de dados}

Como material para a análise de dados, selecionamos uma amostragem do jornal local O Nacional, de Passo Fundo (RS). Escolhemos três meses - abril, julho e setembro de 2011 - de forma aleatória. Selecionamos uma semana de cada um desses três meses, para embasar nossa pesquisa. Essas semanas corresponderam aos dias 25 a 30 de abril, 25 a 31 de julho, 24 a 30 de setembro. 
Nessa amostragem selecionada, não encontramos nenhuma matéria, reportagem, nota ou citação sobre o tema de nosso estudo, gravidez na adolescência. Para complementar a nossa pesquisa, outros passos - não no presente texto - são, como já dito, as avaliações de nossas segunda e terceira amostragens, sobre um periódico de circulação estadual, o jornal Zero Hora, de Porto Alegre (RS), e um jornal nacional, a Folha de S.Paulo.

\section{CONSIDERAÇÕES FINAIS}

Uma das principais ferramentas (se não a principal) para intervir na saúde é a comunicação. No âmbito da saúde, a comunicação diz respeito ao estudo e à utilização de estratégias para informar e para influenciar as decisões dos indivíduos e das comunidades no sentido de promoverem sua saúde.

Essa definição é suficientemente ampla para englobar todas as áreas nas quais a comunicação é relevante em saúde. Não se trata somente de promover a saúde, embora, estrategicamente, essa seja a área de maior importância..

De fato, a comunicação em saúde inclui mensagens que podem ter finalidades muito diferentes, tais como:

- Promover e educar para a saúde;

- Evitar riscos e ajudar a lidar com as ameaças para a saúde;

- Prevenir doenças;

- Sugerir e recomendar mudança de comportamento;

- Recomendar medidas preventivas e atividades de autocuidado;

- Informar sobre a saúde e sobre as doenças.

É visível, assim, que a comunicação em saúde tem influência importante, tanto em nível individual, quanto no nível da comunidade. Em nível individual, ela ajuda a tomar consciência das ameaças à saúde, pode influenciar quanto a mudanças que visam reduzir os riscos, bem como reforça atitudes de comportamentos favoráveis à saúde. No nível da comunidade, pode promover mudanças favoráveis nos níveis socioeconômicos e físicos, melhorar a acessibilidade dos serviços de saúde e facilitar a adoção de normas que contribuam positivamente para a saúde e a qualidade de vida.

Quando falamos em gravidez na adolescência, a importância da comunicação não muda. Segundo dados do Ministério da Saúde, os maiores índices de gravidez na adolescência estão entre os menos favorecidos, com acesso limitado tanto à comunicação e à troca de informações, como 
aos meios de prevenção. O comunicador da saúde tem assim um papel fundamental na busca pela mudança dessa realidade. Seu dever é informar o público (leitor e/ou alvo da intervenção) acerca das consequências trazidas por uma gravidez durante o período da adolescência. Mais do que isso, o comunicador precisa informar também sobre as formas de prevenção, tanto da gravidez, quanto das DSTs.

É importante ter em mente que os promotores da saúde devem estar completamente voltados para a disseminação da prevenção, pois, no caso da gravidez na adolescência, a problemática abordada não é uma doença. É uma consequência que muda totalmente a vida das pessoas.

Há que se apresentar todos os aspectos e todas as mudanças acarretadas pela gravidez, para que, assim, cada adolescente forme sua consciência e, principalmente, esteja ciente das consequências de seus atos. Dessa forma, o dever do comunicador de saúde, como interventor, é informar sobre todos os aspectos, a fim de criar o hábito da prevenção, e não impor ações, porque a percepção que cada pessoa tem sobre o assunto varia de acordo com sua cultura.

Em alguns países, como a China, que não possui mais capacidade territorial para absorver um número elevado de indivíduos, a maternidade é controlada pelo governo e cada casal só pode ter um filho. Em outras culturas, como em tribos indígenas e alguns países africanos, gravidez é sinônimo de saúde, riqueza e prosperidade.

No Brasil, onde não há controle de natalidade e o planejamento familiar e a educação sexual ainda são assuntos pouco discutidos, a gravidez acaba tornando-se, muitas vezes, um problema social grave e de difícil solução. É o caso da gravidez na adolescência.

O fato de não termos encontrado o tema gravidez na adolescência em nenhuma das edições do jornal O Nacional selecionadas para a nossa amostragem, reflete que, em nível local, a mídia não está preocupada com o assunto ou não está dando a ênfase necessária. Alguns comunicadores e veículos consideram esse tema um pouco ultrapassado, porque já foi notícia por diversas vezes. Porém, é necessário lembrar que o público adolescente se renova a cada ano e que, pelo fato de os adolescentes iniciarem cada vez mais cedo sua vida sexual, a preocupação com a prevenção tem que ser constante.

A desinformação e a fragilidade da educação sexual são questões muito problemáticas. As escolas e os sistemas de educação estão muito mais preocupados em trabalhar matérias cobradas no vestibular, como física, química, português, matemática etc., do que em discutir questões de cunho social. Dessa forma, temas como sexualidade, gravidez, drogas, entre outros, ficam restritos, quase sempre, a projetos, feiras de ciência, semanas temáticas, entre outras ações pontuais. Os governos, por sua vez, também se limitam às campanhas esporádicas. Além disso, em geral essas campanhas não primam pela conscientização, mas apenas pela informação a respeito de métodos contraceptivos. 
É por esse motivo que a comunicação da saúde, trabalhada pela mídia, tem tamanha importância. É a forma mais fácil de atingir o maior número de pessoas e fazer com que estas reflitam sobre a gravidez na adolescência, criando uma cultura de prevenção e melhorando seu estilo de vida.

O fato de a mídia local não dar a esse tema a atenção necessária quer dizer muito, pois mostra que os adolescentes com acesso a ela não estão recebendo nenhuma informação acerca de como se prevenirem quanto aos problemas causados pela gravidez na adolescência e pelas doenças sexualmente transmissíveis, dentre outros.

\section{REFERÊNCIAS}

ALCALAY, Rina. La comunicación para la salud como disciplina en las universidades estadounidenses. Panam Salud Pública, v. 5, n. 3, 1999.

BANDURA, Albert. Social learning theory. Englewood Cliffs (NJ): Prentice-Hall, 1977.

Social cognitive theory of mass communication. In: Media effects: advances in theory and research. Hilsdale (NJ); Hove (UK): Lawrence Erlbaum Associates, 1994.

BARDIN, Laurence. Análise de conteúdo. Lisboa: Edições 70, 1977.

BELTRÁN, Luis Ramiro. Promoción de la salud: una estrategia revolucionaria cifrada en la comunicación. Comunicação \& Sociedade, São Bernardo do Campo (SP), PósCom-Umesp, a. 22, n. 35, p. 139-158, 1o. sem. 2001 a.

La importancia de la comunicación en la promoción de la salud. In: MARQUES DE MELO, José et al. (Org.). Midia e saúde. Adamantina (SP): Unesco / Umesp / FAl, 2001b.

BERTOL, Sonia R. Schena. Tarso de Castro, editor de O Pasquim. Passo Fundo (RS): Editora UPF, 2001.

CAPRA, Fritjof. O ponto de mutação: a ciência, a sociedade e a cultura emergente. São Paulo: Cultrix, 1986.

CARVALHEIRO, José R. Os desafios para a saúde. Estudos Avançados, São Paulo: USP, v. 13, n. 35, jan.-abr., p. 7-20. 1999.

GOFFMAN, Erving. Frame analysis: an essay on the organization of experience. Boston: Northeastern University Press, 1986.

IBGE-UNICEF. Indicadores sobre crianças e adolescentes: Brasil, 1991-1996. Rio de Janeiro: IBGE / Unicef, 1997.

KOTLER, Philip; ROBERTO, Eduardo L. Social marketing: strategies for changing public behavior. Nova York: Free Press, 1989.

LIMA, Julie C.; SIEGEL, Michael. The tobacco settlement: an analysis of newspapers coverage of a national policy debate, 1997-98. Tobacco Control, v. 8, p. 247-253, 1999. 
MENASHE, Claudia L.; SIEGEL, Michael. The power of a frame: an analysis of newspaper coverage of tobacco issues. United States, 1985-1996. Journal of Health Communication, Taylor \& Francis Group, n. 3, p. 307-326, 1998.

MEYEROWITZ, Beth E.; CHAIKEN, Shelly. The effect of message framing on breast self -examination attitudes, intentions, and behavior. Journal of Personality and Social Psychology, n. 52, p. 500-510, 1987.

MS - Ministério da Saúde. Portal da Saúde - SUS. Disponível em: <http://portal.saude.gov.br/portal/saude/cidadao/visualizar_texto.cfm?idtxt=259>. Acesso em: 13 jan. 2007.

PINTOS, Virginia Silva. Comunicación y salud. In: Inmediaciones de la Comunicación. Vol 3. Montevidéu: Universidad Ort Uruguay, 2000.

RATZAN, Scott C.; PAYNE, J. Gregory.; BISHOP, Carol. The status and scope of health communication. Journal of Health Communication, v. 1, n. 1, p. 25-41.1996.

ROGERS, Everett M. Diffusion of innovations. 4. ed. New york: The Free Press, 1995. Up-to-date report. Journal of Health Communication, v. 1, n. 1, p. 15-23, 1996.

SALMON, Charles T. Bridging theory "of" and theory "for" communication campaigns: an essay of ideology and public policy. Communication Yearbook, Newbury Park (CA), Sage, v. 15, p.346-358,1992.,

SERRA, José. A questão da saúde no Brasil. Estudos Avançados, São Paulo, USP, v. 13, n. 35, p. 39-50, jan.-abr. 1999.

SOARES, Murilo Cesar. Análise de enquadramento. In: Métodos e técnicas de pesquisa em comunicação. São Paulo: Atlas, 2006.

TUCHMAN, Gaye. Making news: a study in the construction of the reality. New York: The Free Press; London: Collier Macmillan Publishers, 1978.

VARELLA, Drauzio. Gravidez na adolescência. Disponível em: <http://drauziovarella.ig.com.br/entrevistas/gravidez_adolescencia.asp>. Acesso em: 13 jan. 2007.

WICKS, Robert $\mathrm{H}$. Message framing and constructing meaning: an emerging paradigm in mass communication research. Communication Yearbook, Mahwah (NJ); London, v. 29, p. 333-361, 2005.

Recebido em: 05.03.2012 / Aceito em: 04.06.2012 